\title{
ÇEVİRI: Latin harfleriyle yazılmış bir atasözü derlemesi ${ }^{1}$
}

György Hazai

\section{Çev. Beytullah BEKAR²}

Türkologlar, A. Bombaci’nin ilk bilimsel çalışmalarını Türkçenin konuşma dili ile ilgili sorunlara adadığını iyi bilirler. O, Türkçenin Arap harfli olmayan metinlerinin incelenmesi noktasında Argenti ve Ferraguto'nun çalışmalarını yayımlayarak ve inceleyerek bir çı̆̆ır açmıştır. Aşağıda kaleme alınmış olan mütevazı yazı, içerik olarak. A. Bombaci’nin çalışmalarıyla benzer bir Türkçe metinle ilgili olup çok değerli unutulmaz arkadaşım ve meslektaşım A. Bombaci'yi ve çalışmalarını tekrar yâd etmeyi amaçlamaktadır.

Saksonya Devlet Kütüphanesinde (No. Ea 224) Türkçe bir el yazması ve bu el yazmasının 102v-111v sayfaları arasında küçük bir Türkçe atasözleri derlemesi bulunmaktadır. Her bir atasözü sayfanın sol sütununa yazılmış olup sayfanın sağ sütunu boştur. Sayfaların iki sütun halinde bölümlenmiş olmasının nedeni $111 r$ de ortaya çıkmaktadır. 111r'de sayfanın sağ sütununda atasözleri Arap harfleriyle tekrar kaleme alınmıştır. (Bu sebeple H. L. Fleischer'in yazma eserler kataloğunda “.... proverbia turcica, quorum major pars latinis literis scripta est” olarak adlandırılmıştır). Yine bu sayfa, atasözlerinin başka dildeki karşılıklarının verilmiş olması bakımından diğer sayfalardan farklılık göstermektedir. Atasözlerini yazan kişinin amacı büyük ihtimalle derlemedeki diğer sayfaları da aynı şekilde tamamlamaktı fakat bunu gerçekleştiremediği görülür. Bu noktada derlemenin başka sayfalarında Türkçe atasözlerinin bulunduğunu da belirtmek gerekir. 68v-92r sayfalarında konulara göre gruplandırılmış, Latince ve İtalyanca karşılıları verilmiş Arap harfli Türkçe atasözleri bulunmaktadır. (H. L. Fleischer bu bölümü "Proberbia turcica cum versione italica et latina" olarak adlandırmıştır). Fakat buradaki atasözleri bizim makalemizin konusu dışındadır.

Haklı olarak akıllara bu atasözleri derlemesinin hangi tarihe ait olduğu sorusu geliyor. Yazma içinde bir tarih bilgisi yoktur. Sakson Devlet Kütüphanesi el yazmaları bölümünün verilerinde yazmanın elde edilme şekli ve tarihiyle ilgili bir ipucu bulunup bulunmadığı hususundaki bilgi talebim üzerine kütüphane danışmanı H. Deckert bana şu cevabı vermiştir: "Eserin içerisinde eserin yazıldığı tarih ile ilgili bir bilgi yoktur. Fakat eserin içinde geçen bir anlatıda 1689 tarihi verilmiştir. Yazmanın kapağında sahibinin - Mscr. Dresd. Ea. 175 numaralı yazmada da olduğu gibi- M. G. Weideman (1686-1743) olduğu yazılıdır. H. L. Fleischer, hazırlamış olduğu Dresden Kütüphanesi Doğu Yazmaları Kataloğunda, bu eserin de içinde olduğu 49 yazmanın M. G. Weideman tarafından 1728 ile 1732 yılları arasında Viyana'da satın alındığını yazar. Bununla birlikte H. L. Fleischer, M. G. Weideman'ın satın almış olduğu bütün el yazmalarını özelliklerine göre bu katalogda tanıtır. Eserin tahmini olarak 1689 ile 1728 tarihleri arasında yazılmış olabileceğini belirtir3. H. L. Fleischer’e göre eserin sonundaki atasözleri diğer bölümlerden daha geç bir tarihte ve muhtemelen M. G. Weideman tarafindan yazılmıştır.”

\footnotetext{
$1 \quad$ Hazai G. (1982). Eine türkische Sprichwortsammlung in Lateinschrift. Studia Turcologica Memoriae Alexii Bombaci Dicata, Istituto Universitario Orientale Seminario Di Studi Aslatici Series Minor XIX, ss. 263-277.

2 Dr. Öğr. Üyesi, Kırklareli Üniversitesi, Fen Edebiyat Fakültesi, Türk Dili ve Edebiyatı Bölümü, (Kırklareli, Türkiye), beytullahbekar@gmail.com, ORCID ID: 0000-0002-8372-1190 [Makale kaylt tarihi: 18.01.2019-kabul tarihi: 18.02.2019; DOI: $10.29000 /$ rumelide. 541093]

3 Mecmua içinde bir mukataa kaydında H.1068 (M. 1658) tarihi verilmiştir. Bu sebeple mecmua için kütüphane kaydında verilen 1689 tarihi güvenilir değildir.
} 
Bu bilgilerden hareketle Ea 224’te kayıtlı yazmadaki atasözlerinin tarih olarak 18. yüzyılın başlarına dayandığı varsayılabilir.

Devamında Latin harfleriyle yazılmış atasözleri detaylandırılarak listelenmiştir. Her bir atasözü şimdiye kadar yayımlanmış kapsamlı atasözü çalışmalarıyla karşılaştırılmış ve karşılaştırma sonucunda Dresden'deki yazma eserin bu bölümünde bulunan düzinelerce atasözünün bu eserde bulunmadığ 1 tespit edilmiştir4. Atasözlerini tespit etmek ve karşılaştırmak için F. F. Tülbentçi’nin çalışması esas alınmıştır5. Diğer eserlerden ise Tülbentçi’nin çalışmasında benzer atasözü bulunamadığı zaman alıntılama yapılmıştır ${ }^{6}$. Belirlenen çerçeve nedeniyle atasözleriyle ilgili eserlerin tümü taranmamıştır7. Dil incelemesi de aynı sebepten yapılmamıştır. Bunlar başka bir çalışmanın konusu olarak işlenecektir.

(102v)

(1) Ischten artmaz, dischten artar.

(krş.: TAD 8161: İçten ${ }^{8}$ artmaz, dişten artar.)

(2) Isch ischy ghioestürür.

(krş.: TAD 8116: İş işi gösterir.)

(3) Evdēki hisāb, bazarā uymaz.

(krş.: TAD 5836: Evdeki hesap çarşıya uymaz.)

(4) Adzilā edzielī ghielen soyleschür.

(krş.: TAD 117: Ac ile eceli gelen söyleşir.)

(5) Eskiy dost duschmān olmaz.

(krş.: TAD 5619: Eski dost düşman olmaz.)

(6) Bāl bāl dimēghiile aghyz thatlü olmaz.

(krş.: TAD 2138: Bal bal demekle ağız tatlılanmaz.)

(7)* Itisine benghizemejen oghurlukdur.

(TAD: -)

(8) Kiepeneki altünda er jatür.

(krş.: TAD 9194: Kepenek altında er yatar.)

(9) Âk kojūny ghioerēn, itzy dolū jāgh Isanür.

(krş.: TAD 547: Ak koyunu gören içi dolu yağ sanır.)

(10) Ssū bulanmaindzie durulmaz.

(krş.: TAD 12643: Su bulanmayınca durulmaz.)

(11) Jokarü baksam jüzüm afekagha sfakalüm.

(krş.: TAD 14688: Yukarı tükürsem sakalım, aşağı tükürsem bıyığım.)

(12)* Thokuz dzieviz ghioermeyndzie, bir thasch atma.

(TAD: -)

$\mathrm{Bu}$ atasözleri sıra numarasından sonra $(*)$ yıldız işaretiyle gösterilmiştir.

F. F. Tülbentçi, Türk Atasözleri ve Deyimleri, İstanbul 1963.

Ĕger atasözü Tülbentçi'nin eserinde mevcut değilse bu her zaman gösterilmiştir. Tülbentçi'de atasözünün olmadığını gösteren işaretten sonra başka bir kaynak verilmemișse bu atasözünün diğer eserlerde de olmadı ğı anlamına gelmektedir. Karşılaştırma yapılan eserler için kullanılan kısaltmalar: AS = Ö. A. Aksoy, Atasözleri Sözlüğ ü (= Atasözleri ve Deyimler Sözlüğü [I], Ankara 1971 Türk Dil Kurumu Yayınlar. 325/[1]). BAAD - Ö. A. Aksoy, Bölge Ağrzlarmda Atasözleri ve Deyimler [I], Ankara 1969 Türk Dil Kurumu Yayınları. 279/[I]; TAD = F. F. Tülbentçi, Türk Atasözleri ve Deyimleri, İstanbul 1963; TAS = M. N. Özön, Türk Ata Sözleri, İstanbul [1952] 
(13) Melemende kietzi, etine kioeh (?).

(?)

(14) Ikhy oekyza bir ssamāny boelēmez.

(krş.: TAD 7822: İki öküze bir saman verecek hali yok.)

\section{(103r - 103v: boş)}

\section{(104r)}

(1) Kavlsyz durān, hakksyz tzikar.

(krş.: TAD 8905: Kavilsiz giren haksız çıkar.)

(2) Kaschyghyile vyryde, ssapy ile ghioezin tzikarür.

(krş.: TAD 8852: Kaşı̆̆ı ile yedirir, sapı ile göz çıkarır.)

(3) Kūl kulā sebebilür.

(krş.: TAD 9975: Kul kula sebeptir.)

(4) Kāz kāz ile, karā tavuk choros ile kuschy kuschile avlarlar.

(krş.: TAD 8939: Kaz kazla daz dazla, kel tavuz kel horosla; TAD 10201: Kuşu kuşla avlarlar.)

(5) Kyrk sertzieden bir boerēki olmaz.

(krş.: TAD 9337: Kırk serçeden bir börek.)

(6) Kanādsyz kusch uczmaz.

(krş.: TAD 8564: Kanatsız kuş uçmaz.)

(7)* Kapalü aghyzā Singheki ghìrmez.

(TAD: -)

(8) Kuzghunā sormischler ghiendü javrisinā.

(krş.: TAD 10242: Kuzguna sormuşlar: “Güzel kimdir?” "Yavrularımdır” demiş.)

(9) Konuk konūghy sevmēz.

(krş.: TAD 10831: Misafir misafiri sevmez, ev sahibi ikisini de.)

(10)* Kiopek ${ }^{i}$ aghyzin kiemik ${ }^{i}$ tutār.

(TAD: -)

(11)* Ghï̈n ghï̈ny besler.

(TAD: -)

(12) Gh' ${ }^{\mathrm{i} O ̈ z}$ gh ${ }^{\mathrm{i} o e r m e y n d z i e ~ g h}{ }^{\mathrm{i}}$ onghï̈l katlanür. ${ }^{9}$

(krş.: TAD 6536: Göz görmeyince kulak katlanır.)

(13) Ghï̈n doghmazdan evvel neler doghar.

(krş.: TAD 6684: Gün doğmadan neler doğar.)

(14) Kimse kimsenüngh ${ }^{i}$ haliny bilmez.

(krş.: TAD 9510: Kimse kimsenin halini bilmez.)

(15) Ghï̈dz ile ghiuzelliki olmaz.

\footnotetext{
9 Tülbentçi atasözünde 'gönül' yerine 'kulak' yazmış, G. Hazai de o şekilde vermiştir. Fakat atasözünün doğrusu "Göz görmeyince gönül katlanır.”dır. Bakınız E. Kemal Eyüboğlu (1973). Şiirde ve Halk Dilinde Atasözleri ve Deyimler. s. 109. İstanbul: Doğan Kardeş Matbaacılık. ve Ömer Asım Aksoy (1988). Atasözleri ve Deyimler Sözlüğ̈ü I- Atasözleri Sözlüğü. s. 293. İstanbul: İnkılap.
} 
(krş.: TAD 6631: Güç ile gökçeklik olmaz.)

(16) El itziun aghlajān, ghiozsyz olūr.

(krş.: TAD 5355: El için ağlayan gözsüz kalır.)

(17) Aladziagh īle vyredzieki oedenmez.

(krş.: TAD 764: Alacak ile verecek ödenmez.)

(18) Aladziaghiin alamajan, vyredzieghiin vyremez.

(TAD: -)

(19) Ejüliki eyle derjada baluk bilmezsa, chalyk /Allah/ bilür.

(krş.: TAD 8294: İyilik et denize at, balık bilmezse Hâlik, bilir.)

\section{(104v)}

(1) Etme bulma, dunjasydür.

(krş.: TAD 6798: Etme bulma dünyası.)

(2) Escheghy suren osurughüna katlanür.

(krş.: TAD 5731: Eşeği tımarlayan osuruğuna katlanır.)

(3) Av alanünghdür.

(krş.: TAD 1725: Av vuranın değil, alanındır.)

(4) Üzüm üzümy ghioerurek kararür.

(krş.: TAD 13767: Üzüm üzüme baka baka kararır.)

(5) Ssabr ile korùk halvà olūr.

(TAD: 11940: Sabır ile koruk helva olur.)

(6)* Dūd japraghy atlāz olūr.

(TAD: -)

(7) Ikhy karpūz bir kolthigha ssyghmaz.

(krş.: TAD 7808: İki karpuz bir koltuğa sığmaz.)

(8) Korkulù düsch chayrlüdür.

(krş.: TAD 9710: Korkulu düşün sonu hayırlıdır.)

(9) Gharyb kuschüng javrisyny Tanhry japar.

(krş.: TAD 6159: Garip kuşun yuvasını Allah yapar.)

(10) Ghurbetlykda oegienmek ${ }^{i}$ hamamdà türkiüy irlamak ghiby.

(krş.: TAD 6628: Gurbette öğünmek hamamda şarkı okumağa benzer.)

(11) Kurt komschusiny indzitmēz.

(krş.: TAD 10077: Kurt komşusunu incitmez.)

(12) Kūrt kodziaindzia kioepeghin maskarasy olūr.

(krş.: TAD 10076: Kurt kocayınca köpeklerin maskarası olur.)

(13)* Kapunghy peki kapada, Allaha yssmarla.

(TAD: -)

(14)* Jülān seven, dikieninde sever.

(TAD: -) 


\section{(105r)}

(1) El eli jaykār, ikhy el juzy.

(TAD: -; krş.: AS 863: El eli yıkar, iki el yüzü; krş.: ayrıca TAS 3010)

(2) Oinaschina inanan kary ersyz kalür.

(krş.: TAD 11481: Oynaşına güvenen avrat, ersiz kalır.)

(3) Akcziaja akczia kazanür.

(krş.: TAD 573: Akçe akçeyi kazanır.)

(4) Tziok kojunüngh tziok kuzusy olūr.

(krş.: TAD 3870: Çok koyunun çok kuzusu.)

(5)* Oelününgh dost olmaz.

(TAD: -)

(6) Er olūr, ady kalür

(krş.: TAD 5541: Er ölür adı kalır.)

(7) At olur, maydany kalür.

(krş.: TAD 1567: At ölür meydan kalır. Yiğit ölür şan kalır.)

(8) Allah dejèn. mahrùm kalmaz.

(krş.: TAD 912: Allah diyen mahrum kalmaz.)

(9) Azy bilmejen, tziōghy hytz bilmez.

(krş.: TAD 1976: Azı bilmiyen çoğu hiç bilmez.)

(10) Ulù sozingh dinghlemejen oelüja kalür.

(krş.: TAD 13592: Ulu sözü tutmayan uluyu kalır.)

(11)* Ev danesy bughā olmaz.

(TAD: -; BAAD s. 118: Ev danası öküz olmaz.)

(12) Bir tzitzēki ile yāz olmaz.

(krş.: TAD 2747: Bir çiçekle yaz olmaz.)

(13) Atz ajū oynamaz.

(krş.: TAD 104: Aç ayı oynamaz.)

$(14)^{*}$ Eschlü eschyile, tamburā tel ile.

(TAD: -)

$(15)^{*}$ Istejen mevlasin bulūr.

(TAD: -)

(16)* Oelmisch a'rab, azad eylemisch.

(TAD: -)

(17) Oghlan aghlamaindzie meme vyrmezler.

(krş.: TAD 11299: Oğlan ağlamayınca meme vermezler.)

(18) Tauschana kacz, tazyja tūt.

(krş.: TAD 13181: Tavşana kaç, tazıya tut.)

(19) Tyz vyrēn ikhy kierre vyryr.

(krş.: TAD 3549: Çabuk veren iki verir.)

(20) Er lokmasy behanā ile jenür. 
(TAD: -)

\section{(105v)}

(1)* Et ile dery, jemeki ile dīry.

(TAD: -)

(2)* Ikihy jattān ücz kalkār.

(TAD: -)

(3) Ikihy dziambāz bir ipte oynāmaz.

(krş.: TAD 7764: İki cambaz bir ipte oynamaz.)

(4)* Et kiemikisyz olmāz.

(TAD: -)

(5)* Kiemiki ilikisyz olmaz.

(TAD: -)

(6) Aī aidin hisab bellü.

(krş.: TAD 1769: Ay aydın hesap belli)

(7) Insān ikrarynden hayvān jularinden.

(krş.: TAD 7971: İnsan ikrarından, hayvan jularından tutulur.)

(9) Ainaja bakān ghienduna ghioerür.

(krş.: TAD 1915: Aynaya bak da kendini gör.)

(8) Insān inasnüngh ${ }^{i}$ ainasydür.

(krş.: TAD 7975: İnsan insanın aynasıdır.)

(10) El jumrughin jemejen, ghiendü jumrughün bozdoghān ssanür.

(krş.: TAD 5393: El yumruğunu yemeyen kendi yumruğunu Bozdağın armudu sanır: TAD 5394: El yumruğu yemeyen kendi yumruğunu değirmen taşı sanır; krş.: ayrıca TAD 5392)

(11) Eyülikie ejüliki kiemlighie kiemliki bulunūr.

(TAD: -; krş.: AS 1280: İyilik eden iyilik bulur.)

(12) Ejulighie ejuliki olaidy karā oekiüze biczāk olmāzidy.

(krş.: TAD 8308: İyiliğe iyilik olsaydı, kara öküze bıçak olmazdı.)

(13) Ghurbetlykda oeghienmeki hamamdā türkyy irlamak ghiby.

(krş.: TAD 6628: Gurbette öğünmek hamamda şarkı okumağa benzer.)

\section{(106r)}

(1) Az vyren, dzianden vyrir.

(krş.: TAD 1960: Az veren candan verir, çok veren maldan verir.)

(2) Tziok bilen tziok janghylür.

(krş.: TAD 3854: Çok bilen çok yanııır.)

(3) Tzibuk jasch ikien ejüghielür.

(krs..: TAD: -)

(4) Demīr tavenda jakischir.

(krş.: TAD 4256: Demir tavında dövülür.)

(5) Tzirak dibi karanlyk olūr. 
(krş.: TAD 3730: Çıra dibi karanı [karanlık] olur.)

(6) Harekiet olmaduktzie, berekiat olmaz.

(krş.: TAD 6958: Hareket olmayınca bereket olmaz.)

(7)* Hakk bathil olmaz.

(TAD: -)

(8)* Hakk ise ssahibiny bulūr.

(TAD: -)

(9)* Chayr ischte tachtir olmaz.

(TAD: -)

(10) Hastaja doeschekiiny ssorarmysyn?

(krş.: TAD 7012: Hastaya döşek sorulmaz.)

(11) Eskii duschmen dost olmaz, olūrsa da jaraschmaz.

(krş.: TAD 5627: Eski düşman dost olmaz domuz derisinden post olmaz.)

(12) Bosch torbā ile katür tutulmaz.

(krş.: TAD 3108: Boş torba ile at tutulmaz.)

(13) Bāl tutān parmaghin jalar.

(krş.: TAD 2151: Bal tutan parmağını yalar.)

(14) Beyghiden ghielen beyghidür.

(krş.: TAD 2574: Beyden gelen beydir)

(15)* Baghtziabane tochummy ssatarsyn.

(TAD: -)

\section{(106v)}

(1) Oelmisch a'rab azad eylemisch. (krş.: 105r: 16.)

(TAD: -)

(2) Oghlān aghlamaindzie meme vyrmezler. (krş.: 105r: 17.)

(krş.: TAD 11299: Oğlan ağlamayınca meme vermezler.)

(3) Insān yhsān kulydür.

(krş.: TAD 7969: İnsan ihsan kuludur.)

(4) Ikhy kiedi bir arslana bes dür.

(krş.: TAD 7809: İki kedi bir arslana pes dedirir; TAD 7810: İki kedi bir arslana yeter.)

(5) Tauschāna kacz tazyjā tūt. (krş.: 105r: 18.)

(krş.: TAD 13181: Tavşana kaç, tazıya tut.)

(6) Basfkysyz pedevrā jēl alür.

(krş.: TAD 2254: Baskısız pedavrayı el almazsa yel alır.)

(7)* Tēz biten tez jeter.

(TAD: -)

(8) Temelsyz binā tutulmāz.

(krş.: TAD 13267: Temelsiz bina tez yıkılır.)

(9) Tziürüki baklanügh tziurük $k^{i} / k^{i} \bar{r} /$ alydzysy olūr. 
(krş.: TAD 3940: Çürük baklanın kör alıcısı olur.)

(10) Dziān boghazden ghielür.

(krş.: TAD 14043: Can boğazdan gelir.)

(11) Tzifūd ssaghirlaindzie eski defterin joklar.

(krş.: TAD 14043: Yahudi züğürtledikçe eski defterleri karıştırır.)

(12) Tziatal kaschyk ghiby jere ghirmez.

(krş.: TAD 3643: Çatal kazık yere çakılmaz.)

(13) A'rab a'rabā jüzy kara dimisch.

(krş.: TAD 1233: Arap Arap’a yüzün kara demiş.)

(14) Tziok vyren, ghiognülfyz vyrir.

(krş.: TAD 1960: Az veren candan verir, çok veren maldan verir.)

\section{(107r)}

(1) Bir tziplāghy kyrk harāmi sojāmaz.

(krş.: TAD 2744: Bir çıplağı bir hırsız soyamaz.)

(2) Adam zahmetsyz, bal jenmez.

(krş.: TAD 14845: Bal zahmetsiz olmaz.)

(3) Ghiendù ghioezindeghi mertēghy ghioermez, elin ghioezindēghi tziōpy ghioerür.

(krş.: TAD 9141: Kendi gözündeki merteği görmez, elin gözündeki çöpü görür.)

(4) Ghiül dikiensyz olmaz.

(krş.: TAD 6649: Gül dikensiz olmaz.)

(5) Ghï̈nesch baltzyk ile ssyvanmaz.

(krş.: TAD 6724: Güneş balçıkla sıvanmaz.)

(6) Kischy ekidughiny bitzer.

(krş.: TAD 9553: Kişi ektiğini biçer.)

(7) Ghioezden irak olan ghionghüldan da irak olūr.

(krş.: TAD 6565: Gözden rrak olan gönülden dahi ırak olur.)

(8) Kimse joghurdum karādür dimez.

(krş.: TAD 9512: Kimse yoğurdum kara demez.)

(9) Ghiüdz ile süren kioepeki koyunū kurdā kaptürür.

(krş.: TAD 14293: Yavaş köpek sürüye kurt getirir.

(10) Ghionül kimy sevērife, ghiuzel ō dür.

(krş.: TAD 6445: Gönül kimi severse gönül ${ }^{10}$ odur.)

(11) Kioepēghy oeldurene sürürdürlār.

(krş.: TAD 9810: Köpeği öldürene sürütürler.

(12) Kiem soz kiem akczia ssahibinünghdür.

(krş.: TAD 9096: Kem göz kem akçe sahibinindir.

doğrusu: güzel 


\section{(107v)}

(1) Azadzyk aschym, ghavghasyz baschym.

(krş.: TAD 1981: Azıcık aşım, kavgasız başım.)

(2) Burūn juzden düschmez.

(krş.: TAD 3263: Burun yüzden götürülmez.)

(3) Bir babā jighirmy /kirki / oghlū beslemisch ema jighiirmy /kirk/ bir baba beslemezler.

(krş.: TAD 2728: Bir baba dokuz oğlu besler, dokuz oğul bir babayı besliyemez.)

(4) Thauschān daghā kūssmisch, daghin chaber jok.

(krş.: TAD 13170: Tavşan dağa küsmüş, dağın haberi olmamış.)

(5) Babā oghlunā bir bāgh baghischlamisch, oghul babajā bir ssalküm üzüm vyrmemisch.

(krş.: TAD 2016: Baba oğluna bir bağ bağışlamış, oğlu babasına bir salkım üzümü vermemiş.)

(6) Bitziak ssapiny junmaz.

(krş.: TAD 2612: Bıçak kendi sapını kesmez.)

(7) Byjuki baschüngh byjüki aghrisy olūr.

(krş.: TAD 3306: Büyük başın büyük olur ağrısı)

(8) Pektēn tzükmaz joktan tzükār.

(krş.: TAD 1974: Azdan az kalır, çoktan çok.)

(9) Baghschisch atinüng dischlery bakylmaz.

(krş.: TAD 2097: Bahşiş atın dişine bakılmaz.)

(10) Jarynki thaukten bughï̈nki jumurta ejudür.

(krş.: TAD 14240: Yarınki tavuktan bugünkü yumurta iyidir.)

(11) Baschtan murād olān beghünghdür.

(TAD: -)

(12) Balüki baschindan kokār.

(krş.: TAD 2190 Balık baştan kokar.)

\section{(108r)}

(1) Duschmenüngh karindzie ise, merdane ghioēr.

(krş.: TAD 5010: Düşman karınca ise kendini merdane bil.)

(2) Dost baschā bakar, duschmen ajaghā.

(krş.: TAD 4765: Dost başa, düşman ayağa bakar.)

(3) Deliden ve uschakten usslu chaber.

(krş.: TAD 4209: Deliden uslu haber.)

(4) Dōst dostüngh ssararin istemez.

(TAD: -; krş.: TAS 2759: Dosttan zarar gelmez.)

(5) Dilendzinüngh bir juzū karā, vyrmejenüngh ikhy juzū karā.

(krş.: TAD 8091: İsteyenin bir yüzü kara, vermeyenin iki yüzü.)

(6) Dil esen, basch esen.

(krş.: TAD 4502: Dil esen baş esen.)

(7)* Dokiülen ssù kabiny doldurmaz. 
(TAD: -; BAAD s. 98: Dökülen su kabını doldurmaz.)

(8)* Demirdzinüngh akciasy kiümürde.

(TAD: -; krş.: TAS 2441: Demirciden kömür alınmaz.)

(9) Delì oldürki ghiendü, ghiendü dingler ve ghiüler.

(krş.: TAD 4197: Deli oldurki kendi söyler kendi işitir.)

(10) Tilkinüngh varadziāghy kiürkiczy dükianünde; boghdāy doene doene varadziāghy deghirmendür.

(krş.: TAD 13377: Tilkinin dolaşıp geleceği yer kürkçü dükkanıdır.)

(11) Dilüngh kiemighy jok, istedighiin soyler.

(krş.: TAD 4531: Dilin kemiği yok bildiğini söyler.)

(12) Düschinde aghlajān üjanür ghï̈ler.

(TAD: -)

\section{(108v)}

(1) Kiendü düschen aghlamaz.

(krş.: TAD 9131: Kendi düşen ağlamaz.)

(2) Ghionghül dostin bilür.

(krş.: TAD 6434: Gönül dostunu bilir.)

(3) Ghioer, ghiecz, soyleme.

(TAD: -)

(4) Ghioeze japak ${ }^{11}$ olmaz.

(krş.: TAD 6574: Göze yasak olmaz.)

(5) Kischinüngh iradeti kiendü elindedür.

(krş.: TAD 9613: Kişinin iradeti kendi elindedir.)

(6) Ghiereklü ghierekimezikien lazüm olūr.

(krş.: TAD 6324: Gereği gerekmez iken bir gün gerek olur.)

$(7)^{*} \mathrm{Gh}^{\mathrm{i} e l}$ doenen jere doenme.

(TAD:-)

(8) Lakyrdy ile pilauv bischmez.

(krş.: TAD 10380: Lakırdı ile pilav olmaz; TAS 5772: Lakırdı ile pilav pişmez.)

(9)* Meymūn duzak ile tutulmaz.

(TAD: -)

(10)* Muhabbet ghioermekiten ghielür.

(TAD: -)

(11)* Meschrīky bilmejen, maghrīby ne bilsien.

(TAD: -)

(12) Chyrsyz chyrsyze joldaschtür.

(krş.: TAD 7495: Hırsız hırsıza yoldaştır.)

(13) Scheythān kiendü evin jykmaz.

(krş.: TAD 12881: Şeytan kendi evini yıkmaz.)

doğrusu: yasak 


\section{(109r)}

(1) Singheki murdār deghï̈l, ema mi‘dei bulandürür.

(krş.: TAD 12444: Sinek mundar değil ama mide bulandırır.

(2) Ssujy baschinden avlamak ghierek.

(krş.: TAD 12701²: Suyu başından tutmak gerek.)

(3) Schery-'at kiestūghy parmak adzimaz.

(krş.: TAD 12860: Seriatın kestiği parmak acımaz.)

(4) Ssakinān ghioeze tziop düscher.

(krş.: TAD 12088: Sakınılan göze çöp düşer.)

(5) Ssarp sirkie ghiendü kabuna zarār.

(krş.: TAD 12195: Sarp sikke13 kabına zarardır. )

(6) Songh-peschimanlyk fayda etmez.

(krş.: TAD 12519: Son pişmanlık fayda etmez.)

(7) Dolù kap ssū almaz.

(krş.: TAD 4719: Dolu bardak su almaz.)

(8) Damlaja damlaja ghioel olūr.

(krş.: TAD 4051 Damlaya damlaya göl olur; krş.: yine TAD 4052, 4053.)

(9) Tok acz halinden bilmez.

(krş.: TAD 13388: Tok acın halinden bilmez.)

(10) Tasch jerinde aghirdür.

(krş.: TAD 13117: Taş yerinde ağırdır.)

(11) A`kyl a'kylden üstündur.

(krş.: TAD 60o: Akıl akıldan üstündür.)

(12) A‘jybsyz jār istejen, jārsyz kalür.

(krş.: TAD 1909: Ayıpsız yar isteyen yarsız kalır.)

(13) Vyren elli kiesmezler.

(krş.: TAD 13899: Veren eli kimse kesmez.)

(14) Ne oelczy ile oelczersen, ol oelczy ile alürsen.

(TAD: -; krş.: 111r : 3)

\section{(109v)}

(1)* Dostlār arasinda tekilyf joktür.

(TAD: -)

(2) Düschmenüngh ${ }^{i}$ chōr bakma.

(TAD: -; krş.: AS 831: Düşmanın karınca ise de hor bakma.)

(3) Düschmenüngh karindzie ise, fil ghiby ssāy.

(krş.: TAD 5011: Düşman karınca ise sen fil san.) 
(4) Dost ile jē, itz, ema alisch vyrisch etme.

(krş.: TAD: 4780: Dost ile ye iç, alış veriş etme.)

(5) Düghï̈n eviny bilmez, tzianak tziumleki taschir.

(krş.: TAD 4855: Düğün evini bilmez çanak çömlek taşır.)

(6)* Dervisch nerede ahschamlārisa, sarāi ō.

(TAD: -)

(7) Delije hēr ghī̄n bayramdür.

(krş.: TAD: 4221: Deliye göre her gün bayram.)

(8) Zōr ojūny bozār.

(krş.: TAD 15033: Zor oyunu bozar.)

(9)* Singhieki fil olūr.

(TAD: -)

(10)* Schahüngh juvasinda karghā oetmez.

(TAD: -)

(11) Ssū ujūr, duschman ujumaz.

(krş.: TAD 12674: Su uyur, düşman uyumaz.)

\section{(110r)}

(1) Jerdekii juzū kiimse bakmaz.

(krş.: TAD 14463: Yerdeki yüze kimse bakmaz.)

(2) Joldzyjā jōl jaraschir.

(krş.: TAD 14667: Yolcuya yol gerek.)

(3) Jalinghyz tasch dyvār olmaz.

(krş.: TAD 14117: Yalnız taş duvar olmaz.)

(4) Jalinghyz elin sadasy tzikmāz.

(krş.: TAD 14109: Yalnız elin şakırtısı olmaz.)

(5) Jēl esmeindzie japrak kymyldanmāz.

(krş.: TAD 14281: Yel esmeyince çöp kımıldamaz.)

(6) Jejēn bilmez, doghrajān bilür.

(krş.: TAD 14424: Yiyen bilmez, doğrayan bilir.

(7) Jazydzy kiendüne kiem jazmaz.

(krş.: TAD 14346: Yazıcı kendine kem yazmaz.)

(8)* Jēr jerden kutlūdür.

(TAD: -)

(9) Jeramaza kiendü belasy jetischür.

(krş.: TAD 14213: Yaramaza kendi belası yeter.)

(10) Javri kuschüngh aghyzi büjüki olūr.

(krş.: TAD 295: Yavru kuşun ağzı büyük olur)

(11) Jemischüngh ejüsiny donghuz jer.

(krş.: TAD 14437: Yemişin iyisini domuz yer.) 
(12) Ata karin jighiitde burun.

(krş.: TAD 1627: Atta karın yiğitte burun.)

(13) It bok jemēghiile denghyz murdār olmaz.

(TAD: -)

\section{(110v)}

(1) Thavylungh ${ }^{i}$ sesy uzaktan büjüki ghielür.

(krş.: TAD 4108: Davulun sesi uzaktan hoş gelir)

(2) Dār jerde jemeki jemeden, bōl jerde kioetek jemek ${ }^{i}$ jekitür.

(krş.: TAD 4067: Dar yerde yemek yemekten ise bol yerde dayak yemesi hayırlıdır.)

(3) Aschüka Baghdād irak deghïul.

(krş.: TAD 1471: Aşığa Bağdat ırak değildir)

(4) A'rife bīr ghï̈l jetür.

(krş: TAD 1284: Arif isen bir gül yeter kokmaya, hammal isen gir bahçeye yıkamaya.)

(5) Ne schīsch jansun ne kiebab.

(krş.: TAD 11128: Ne şiş yansın, ne kebap.)

(6)* Yrmaki14 almaghin kadaschydür.

(TAD: -)

(7) Vyresyje scherab itzen, ikhy kierre serchosch olūr.

(krş.: TAD 13912: Veresiye şarap içen iki kerre sarhoş olur.)

(8) Hind-istān filly sivri singhekitēn korkār.

(krş.: TAD 7559: Hindistan fili sivri sinekten korkar)

(9)* Hēr kies kulaghin arār.

(TAD: -)

(10)* Ghiezen kurt ile jatān kurt ile bīr deghiüldür.

(TAD: -)

\section{(111r)}

(1) Assyl azmaz, bal ighmez, kürk jyl beslesyn, beghìr āt olmāz.

(TAD: 1386: Azll azmaz, bal kokmaz)

(2)* Syklyghile ghilen zorthile ghiider.

(TAD: -)

(-) Ben dimek şeyțān işidir ${ }^{15}$.

(?)

(3)* Oelczdughinghyz oelczy ile syze ghiirü oelczülmisch olūr.

(TAD:- ; karş. 109r: 14.)

(4) ${ }^{*}$ Esighy $^{16}$ gh $^{\mathrm{i} o e r u p}$ mertek ${ }^{\mathrm{i}}$ ssanür.

(TAD: -) 
(5) Bilek ${ }^{i}{ }^{17}$ eylejen alūr ve thalap iden bulūr ve dakk eylejene aczilmisch olā.

(TAD: -)

(6)* Bīr miskal helal jekirekitür bīr dāgh aghry haramden.

(TAD: -)

\section{(111v)}

(1)* Escheki za'-frāntzi basched.

(TAD: -)

(2)* Indzie eleghüm kanda assajim.

(TAD: -)

(3) Elin atughy tasch uzak duscher.

(TAD 5423: Elin attığı taş uzak düşer.)

(4) Jaramāz ile jār olma.

(TAD 14214: Yaramazla yar olma, iyilerden ibret al.)

(5) Bosch itte menzil olmaz.

(TAD 3099: Boş ite menzil olmaz.)

(6) Itte dalanmaktan tzialy dolanmaktzydür.

(TAD 8221: İte dalaşmadan çalıyı dolaşmak yeydir.)

(7) Janghschāghy ssaghyr fikier ${ }^{18}$.

(TAD 14162: Yanşağın belini sagır bilir)

(8) Ikhì funduk bīr dzievizüngh denkiy dür.

(TAS 4501: İki findık bir olsa bir kozun başını yarar.)

(9) Chayn chafly olūr.

(TAD 6814: Hain adam korkak olur)

(10)* Hēr it ossurdukczie bīr jalan soylersyn.

(TAD: -)

(11) Joghūn indizielindzie, indzie uzulūr.

(TAD 14602: Yoğun incelince ince üzülür ${ }^{19}$.)

Orijinal metindeki yazılışı: Dilek

Orijinal metindeki yazılışı: $\mathrm{s}^{*} \mathrm{k}^{\mathrm{i}} \mathrm{er}$

G. Hazai makalesinde uzulur şeklinde vermiştir. Fakat Tülbentçi’nin eserinde üzülür şeklinde geçmektedir. Üzülür: kırllır, kopar, ayrilır. 